\title{
Characterization and genotyping of strains of Francisella tularensis isolated in Bulgaria
}

\author{
Correspondence \\ Krustyu T. Marinov \\ krustju_marinov@yahoo.com
}

Received 13 May 2008

Accepted 30 August 2008

\author{
Krustyu T. Marinov, ${ }^{1}$ Elena D. Georgieva, ${ }^{1}$ Ivan N. Ivanov ${ }^{2}$ \\ and Todor V. Kantardjiev ${ }^{2}$ \\ ${ }^{1}$ Military Medical Academy, Georgy Sofiisky Blvd 3, Sofia, Bulgaria \\ ${ }^{2}$ National Centre of Infectious and Parasitic Diseases, Sofia, Bulgaria
}

\begin{abstract}
A tularaemia focus was detected in 1998 in Bulgaria, in an area where tularaemia had never been reported. The properties of Francisella tularensis subsp. holarctica strains isolated from 1998 to 2005 were studied. The strains showed heterogeneity, based on acid production from glycerol and erythromycin susceptibility. Genotyping by analysis of seven loci containing variable-number tandem repeats showed four genotypes among eight strains.
\end{abstract}

\section{INTRODUCTION}

Tularaemia is a zoonotic infection. In humans, the disease is usually severe and occasionally fatal. The causative agent, Francisella tularensis, is a Gram-negative, aerobic bacterium. Currently, there are four recognized subspecies (tularensis, holarctica, mediasiatica and 'novicida') (Sjöstedt, 2005). Most cases of tularaemia are caused by F. tularensis subsp. tularensis or subsp. holarctica. F. tularensis subsp. tularensis is distinctly more virulent than the other subspecies. In Europe, only F. tularensis subsp. holarctica has been isolated. There is a single report of isolation of F. tularensis subsp. tularensis from rodents in Slovakia (Gurycova, 1998). Tularaemia in Europe does not generally cause human mortality.

Genetic and phenotypic heterogeneity among the species is limited. F. tularensis subsp. holarctica can be distinguished from F. tularensis subsp. tularensis on the basis of its inability to produce acid from glycerol, the absence of citrulline ureidase activity and its moderate virulence in rabbits (Olsufjev \& Meshcheryakova, 1982; Sjöstedt, 2005). In contrast, $F$. tularensis subsp. tularensis strains produce acid from glycerol, show citrulline ureidase activity and are highly virulent for rabbits. F. tularensis is susceptible to quinolones, aminoglycosides and tetracyclines. Differentiation of erythromycin-susceptible and erythromycin-resistant $F$. tularensis subsp. holarctica strains has been described and is associated with geographical distribution (Olsufjev \& Meshcheryakova, 1982).

Several tularaemia epidemics have been reported in Europe over the last 10 years (Anda et al., 2001; Eliasson et al., 2002; Reintjes et al., 2002; Celebi et al., 2006). There was a tularaemia focus in northern Bulgaria during the 1960s (Dinev \& Zlatanov, 1972). No more cases were reported

Abbreviations: MLVA, multilocus variable-number tandem repeat analysis; VNTR, variable-number tandem repeat. until 1997, when an outbreak occurred in 1997-1998 in western Bulgaria and a new focus was detected. From October 1997 to April 2007, 298 cases of tularaemia were registered. More than $95 \%$ of the patients had the oropharyngeal form of the disease (Kantardjiev et al., 2006).

The purpose of this study was to characterize F. tularensis strains isolated in a new focus of tularaemia, in an area where this infection has not been reported previously.

\section{METHODS}

Strains and growth conditions. Eight Bulgarian F. tularensis strains isolated from 1998 to 2005 were used in this study (Table 1). With the exception of L2, all of the strains were isolated from three villages (Slivnitsa, Breznik and Meshtitsa) or their vicinity. The distance between each was no more than $25 \mathrm{~km}$. More than 100 tularaemia cases were registered in this area. Strain L2 was isolated in northern Bulgaria, in an area about $250 \mathrm{~km}$ away. The isolates were investigated in comparison with nine $F$. tularensis strains of different geographical origins (Table 2). The control strains were supplied by the Bulgarian Type Culture Collection. All strains investigated were identified by immunofluorescence assay and by PCR using primers TUL4-435 and TUL4-863 (Sjöstedt et al., 1997). Bacteria were grown on glucose-cysteine blood agar (GCBA), containing $40 \mathrm{~g}$ blood agar base (Merck) $1^{-1}, 500 \mathrm{mg} \mathrm{L-cysteine.HCl} 1^{-1}, 5 \%$ human blood and $1 \%$ glucose at $37{ }^{\circ} \mathrm{C}$.

Cultural and biochemical characterization. The requirement for cysteine for growth was tested on GCBA and on the same medium without cysteine.

The test for oxidase activity was performed using Kovacs' reagent. The production of $\mathrm{H}_{2} \mathrm{~S}$ was estimated on GCBA with $1.8 \mathrm{~g}$ cysteine $1^{-1}$ using lead acetate strips and on triple-sugar iron agar.

The production of acid from carbohydrates was estimated on solid bloodless medium, containing $20 \mathrm{~g}$ blood agar base $1^{-1}, 1.8 \mathrm{~g} \mathrm{~L}$ cysteine. $\mathrm{HCl} 1^{-1}, 0.9 \mathrm{~g}$ DL-histidine $1^{-1}, 0.2 \mathrm{~g}$ haemin $1^{-1}, 0.01 \mathrm{~g}$

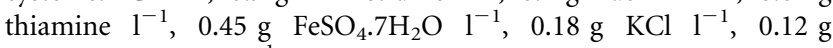
bromothymol blue $1^{-1}$ and $2 \%$ glucose, $2 \%$ glycerol or $2 \%$ sucrose. 
Table 1. Characteristics of $F$. tularensis subsp. holarctica strains isolated in a new focus of tularaemia in Bulgaria

\begin{tabular}{|llcc|}
\hline $\begin{array}{l}\text { Source, year } \\
\text { of isolation }\end{array}$ & Strain & $\begin{array}{c}\text { Acid production } \\
\text { from glycerol }\end{array}$ & ES $^{*}$ \\
\hline Hare, 1998 & L1 & No & R \\
Tick, 1998 & Dm1 & No & R \\
Tick, 1998 & Dm2 & No & R \\
Tick, 1999 & B1 & Yes & S \\
Tick, 1999 & B2 & Yes & S \\
Common vole, 2003 & MMM & No & R \\
Human, 2003 & MN & No & R \\
Hare, 2005 & L2 & Yes & R \\
\hline
\end{tabular}

${ }^{\star}$ ES, Erythromycin susceptibility: S, MIC $\leqslant 2 \mathrm{mg} \mathrm{l}^{-1} ; \mathrm{R}, \mathrm{MIC}$ $>256 \mathrm{mg} \mathrm{l}^{-1}$.

The $\mathrm{pH}$ of the medium was adjusted to 7.4 . This medium is a modification of a liquid medium described previously (Sandström et al., 1992). Additionally, growth on cysteine blood agar was estimated in comparison with growth on cysteine blood agar supplemented with $2 \%$ glycerol or $2 \%$ glucose. All tests were repeated at least five times for all strains, in separate experiments.

Citrulline ureidase activity was estimated on the basis of conversion of citrulline to ornithine.

Bacterial suspensions $\left(\sim 10^{10}\right.$ bacteria $\left.\mathrm{ml}^{-1}\right)$ in PBS (pH 6.5)

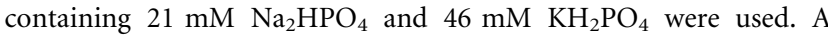
$500 \mu \mathrm{l}$ sample of the suspension was mixed with $500 \mu \mathrm{l} 50 \mathrm{mM} \mathrm{L}-$ citrulline and incubated for $22 \mathrm{~h}$ at $30^{\circ} \mathrm{C}$. The mixtures were centrifuged and the supernatant was removed and sterilized by heating for $20 \mathrm{~min}$ at $100{ }^{\circ} \mathrm{C}$. L-Citrulline and ornithine in the supernatant were separated by paper electrophoresis. We used electrophoresis for $1 \mathrm{~h}$ at $15 \mathrm{~V} \mathrm{~cm}^{-1}$ in phosphate buffer ( $\mathrm{pH} 6.0$ ) containing $8 \mathrm{mM} \quad \mathrm{Na}_{2} \mathrm{HPO}_{4}$ and $59 \mathrm{mM} \quad \mathrm{KH}_{2} \mathrm{PO}_{4}$. Whatman chromatography paper 4 was used and $5 \mu$ spots of samples were applied. Controls consisted of standard solutions of L-citrulline and Lornithine, and supernatants of bacterial suspensions incubated without L-citrulline were included. Following drying, the amino acids bands were located by spraying with a ninhydrin solution $(0.1 \%, \mathrm{w} / \mathrm{v}$, in $95 \%$ ethanol) and heating at $80{ }^{\circ} \mathrm{C}$ for $10 \mathrm{~min}$. A sample was considered to be positive when a clearly visible band of ornithine appeared.

Table 2. F. tularensis control strains used in this study

\begin{tabular}{|ll|}
\hline Strain & \multicolumn{1}{c|}{ Origin } \\
\hline F. tularensis subsp. holarctica & \\
Sweden & Sweden \\
Norway & Norway, 1953, tick \\
Chateauroux & France, 1952, hare \\
Gaiski-15 & Russia \\
$597-73$ & China, 1957 \\
KF-479 & USA, 1958 \\
F. tularensis subsp. tularensis & \\
Schu & USA, 1949, human \\
8859 & USA, 1958, horse \\
O-284 & USA, 1959 \\
\hline
\end{tabular}

Virulence determination. The virulence of each of the Bulgarian isolates was tested in ten white mice. Five mice were subcutaneously inguinally inoculated with suspensions in saline containing 10-20 cells, and five mice were inoculated with 100-200 cells. To investigate virulence in rabbits, groups of three animals were inoculated with $\sim 10^{5}$ or $\sim 10^{6}$ bacteria. Three F. tularensis subsp. tularensis control strains were inoculated with $\sim 10^{2}$ bacteria. The cell number was determined by colony counts on GCBA. All animals were observed for 20 days.

Spleen tissue samples from animals that did not survive the infection were examined by an immunofluorescence assay. Infection in the surviving rabbits was confirmed by a serological assay.

Molecular subspecies identification. Subspecies identification by PCR was carried out by amplification of regions of differences as described previously (Broekhuijsen et al., 2003). This method allows differentiation of the four subspecies of F. tularensis.

Antibiotic susceptibility testing. In vitro susceptibility to ciprofloxacin, gentamicin and erythromycin was determined using Etests (AB Biodisk) on GCBA plates. The inoculum was adjusted to the density of a McFarland 0.5 turbidity standard and resulted in confluent growth. MICs were estimated after incubation for $48 \mathrm{~h}$ at $37^{\circ} \mathrm{C}$.

Genotyping. Strain genotyping was performed by analysis of seven loci containing variable-number tandem repeats (VNTRs) (Johansson et al., 2004). Previously, it has been shown that six of these VNTR markers are discriminative for F. tularensis subsp. holarctica (Byström et al., 2005). Multilocus VNTR analysis (MLVA) was performed as described previously (Gürcan et al., 2008).

\section{RESULTS AND DISCUSSION}

\section{Characteristics and subspecies identification of the isolates}

All strains included in this study showed a requirement for cysteine for growth, the absence of oxidase activity, production of $\mathrm{H}_{2} \mathrm{~S}$ on GCBA and the absence of $\mathrm{H}_{2} \mathrm{~S}$ production on triple-sugar iron agar. Five of the isolates were negative for acid production from glycerol, as were all of the F. tularensis subsp. holarctica control strains used. Three isolates showed acid production from glycerol (Table 1) similar to the $F$. tularensis subsp. tularensis control strains used. All of the glycerol-positive strains grew on the bloodless medium with glycerol and acidified the medium, although growth was not abundant. On cysteine blood agar without glycerol, these strains formed whitish colonies, without a change in the medium. On cysteine blood agar with glycerol, the colonies were grey, distinctly larger and surrounded by a greenish discoloration of the medium. The more abundant growth and the change in the medium were probably a result of degradation of glycerol and acid production, respectively. The growth of the strains negative for acid production from glycerol was not affected by the addition of glycerol. The reproducibility of the tests was good. All strains investigated showed acid production from glucose, estimated by the same methods. No strain produced acid from sucrose. Citrulline ureidase activity 
was found only in the F. tularensis subsp. tularensis control strains.

All Bulgarian isolates were highly virulent for white mice and moderately virulent for rabbits. The lethal dose for mice was $\leqslant 20$ bacteria for seven strains and $<10^{2}$ bacteria for one strain. The rabbits survived infection with $\sim 10^{5}$ bacteria, but infection with $\sim 10^{6}$ cells was lethal. In contrast, the virulence of the $F$. tularensis subsp. tularensis control strains for rabbits was $<10^{2}$ cells. In all cases of lethal infection, the animals survived for no longer than 10 days.

Subspecies identification by PCR showed amplification of characteristic fragments of $\sim 0.9 \mathrm{~kb}$ (Broekhuijsen et al., 2003) in the Bulgarian strains and the F. tularensis subsp. holarctica control strains. Fragments of $\sim 1.5 \mathrm{~kb}$ were amplified in the F. tularensis subsp. tularensis strains.

The characteristics of the strains isolated showed that they belong to $F$. tularensis subsp. holarctica. Three strains produced acid from glycerol. This is an unusual finding and, to our knowledge, is the first report of such a phenotype in European F. tularensis subsp. holarctica strains. The ability to produce acid from glycerol in some of the Bulgarian F. tularensis subsp. holarctica strains could be explained by the possible recovery of certain metabolic pathways due to reverse mutations. An alternative explanation might be that the Bulgarian F. tularensis subsp. holarctica subpopulation had undergone divergent evolution and the metabolic pathways remained intact. In this case, the ability to produce acid from glycerol may represent the ancestral state, as in F. tularensis subsp. tularensis. Thus, at least in the Balkan Peninsula, there is the possibility that some $F$. tularensis subsp. holarctica strains may be misidentified as the highly virulent $F$. tularensis subsp. tularensis on the basis of acid production from glycerol.

\section{Antibiotic susceptibility}

For our isolates, the MICs of ciprofloxacin ranged from 0.023 to $0.064 \mathrm{mg} \mathrm{l}^{-1}$. The MICs of gentamicin ranged from 0.023 to $0.250 \mathrm{mg} \mathrm{l}^{-1}$. For the control strains, the MICs of ciprofloxacin and gentamicin ranged from 0.004 to $0.047 \mathrm{mg}^{-1}$ and from 0.016 to $0.125 \mathrm{mg} \mathrm{l}^{-1}$, respectively. The MICs found were similar to those reported previously in Europe (Ikäheimo et al., 2000). The MICs of erythromycin for the F. tularensis subsp. holarctica control strains were $>256$ or $\leqslant 6 \mathrm{mg} \mathrm{l}^{-1}$. The MICs for six of the Bulgarian isolates were $>256 \mathrm{mg} \mathrm{l}^{-1}$ and for two of the isolates were $\leqslant 2 \mathrm{mg} \mathrm{l}^{-1}$ (Table 1).

\section{MLVA}

MLVA showed four genotypes represented among the eight strains (Fig. 1). Three genotypes were found among the five strains isolated in 1998 and 1999. Two strains isolated in 2003 did not show additional genotypes. However, a strain isolated in 2005 in an area $250 \mathrm{~km}$ away presented with a

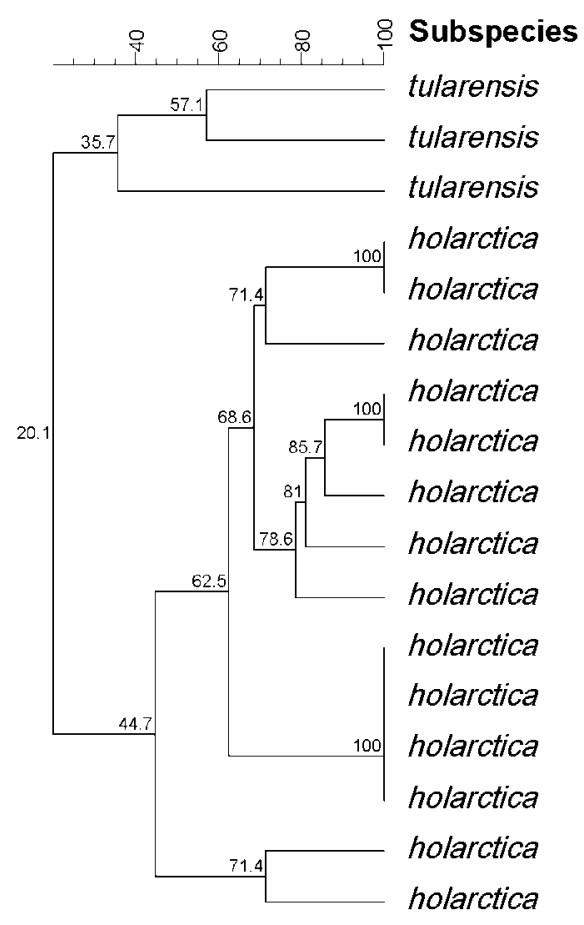

Strain
Schu, USA, 1949 human
8859, USA, 1958, horse
0-284, USA, 1959
Dm1, BG, 1998, tick
Dm2, BG, 1998, tick
Norway, 1953, tick
B2, BG, 1999, tick
B1, BG, 1999, tick
Chateauroux, France, 1952, hare
L2, BG, 2005, hare
Sweden
L1, BG 1998, hare
MN, BG, 2003, human
MMM, BG, 2003, common vole
Gaiski-15, Russia
KF-479, USA, 1958
597-73, China, 1957

$\begin{array}{lllllll}\text { M3 } & \text { M6 } & \text { M10 } & \text { M20 } & \text { M21 } & \text { M22 } & \text { M24 } \\ 432 & 311 & 617 & 255 & 403 & 242 & 459 \\ 378 & 311 & 473 & 255 & 417 & 242 & 459 \\ 306 & 311 & 345 & 471 & 403 & 248 & 459 \\ 333 & 374 & 361 & 255 & 396 & 254 & 480 \\ 333 & 374 & 361 & 255 & 396 & 254 & 480 \\ 288 & 353 & 361 & 255 & 396 & 254 & 480 \\ 297 & 311 & 361 & 255 & 396 & 254 & 480 \\ 297 & 311 & 361 & 255 & 396 & 254 & 480 \\ 297 & 311 & 361 & 255 & 396 & 254 & 459 \\ 297 & 332 & 361 & 255 & 396 & 254 & 480 \\ 360 & 311 & 361 & 255 & 396 & 254 & 480 \\ 351 & 311 & 361 & 267 & 396 & 254 & 480 \\ 351 & 311 & 361 & 267 & 396 & 254 & 480 \\ 351 & 311 & 361 & 267 & 396 & 254 & 480 \\ 351 & 311 & 361 & 267 & 396 & 254 & 480 \\ 378 & 353 & 361 & 255 & 396 & 248 & 459 \\ 396 & 311 & 361 & 255 & 396 & 248 & 459\end{array}$

Fig. 1. Dendrogram based on cluster analysis of seven VNTR (MLVA) loci (M3, M6, M10, M20, M21, M22 and M24). The size obtained for each locus is given in bp. 
different genotype (L2; Fig. 1). Three alleles were found in the highly variable M3 VNTR locus, three alleles were found in the M6 locus and two alleles in the M20 locus (Fig. 1). Some strains isolated in a common area (L1, Dm1 and Dm2) in 1998 differed in their alleles for these three loci. The Bulgarian strains represented a heterogeneous group and some were more closely related to other European strains. The results showed high genetic diversity among these strains distributed in a new disease focus. This is comparable to the genetic diversity of strains isolated in tularaemia-endemic areas and was unexpected in a new focus, where a common parental strain is more likely (Farlow et al., 2001).

The erythromycin-susceptible strains that were positive for acid production from glycerol were identical. These strains and erythromycin-resistant strains that were positive for acid production from glycerol appeared to be closely related, but showed distinct MLVA genotypes.

Investigation of the strains isolated in the outbreak focus showed high phenotypic and genotypic heterogeneity. We suggest that strains with different properties were distributed simultaneously in the area of the focus, probably because of ecological changes in Eastern Europe and the spread of F. tularensis vectors. Another possible explanation is a long-existing epizooty or preservation of the causative agent in other ecological niches, prior to the epidemic.

\section{ACKNOWLEDGEMENTS}

We thank K. Mladenov and V. Kasovski for their contributions to this study.

\section{REFERENCES}

Anda, P., Segura del Pozo, J., Díaz García, J. M., Escudero, R., García Peña, F. J., López Velasco, M. C., Sellek, R. E., Jiménez Chillarón, M. R., Sánchez Serrano, L. P. \& other authors (2001). Waterborne outbreak of tularaemia associated with crayfish fishing. Emerg Infect Dis 7, 575-582.

Broekhuijsen, M., Larsson, P., Johansson, A., Bystrom, M., Eriksson, U., Larsson, E., Prior, R. G., Sjostedt, A., Titball, R. W. \& Forsman, M. (2003). Genome-wide DNA microarray analysis of Francisella tularensis strains demonstrates extensive genetic conservation within the species but identifies regions that are unique to the highly virulent F. tularensis subsp. tularensis. J Clin Microbiol 41, 2924-2931.

Byström, M., Böcher, S., Magnusson, A., Prag, J. \& Johansson, A. (2005). Tularemia in Denmark: identification of a Francisella tularensis subsp. holarctica strain by real-time PCR and high-resolution typing by multiple-locus variable-number tandem repeat analysis. J Clin Microbiol 43, 5355-5358.

Celebi, G., Baruönü, F., Ayoğlu, F., Cinar, F., Karadenizli, A., Uğur, M. B. \& Gedikoğlu, S. (2006). Tularemia, a reemerging disease in northwest Turkey: epidemiological investigation and evaluation of treatment responses. Jpn J Infect Dis 59, 229-234.

Dinev, T. \& Zlatanov, Z. (1972). Bacteriological study of a natural focus of tularemia in the Lake Reserve of Srebrna, the Silistra region, Bulgaria. J Hyg Epidemiol Microbiol Immunol 16, 341-345.

Eliasson, H., Lindbäck, J., Nuorti, J. P., Arneborn, M., Giesecke, J. \& Tegnell, A. (2002). The 2000 tularemia outbreak: a case-control study of risk factors in disease-endemic and emergent areas, Sweden. Emerg Infect Dis 8, 956-960.

Farlow, J., Smith, K. L., Wong, J., Abrams, M., Lytle, M. \& Keim, P. (2001). Francisella tularensis strain typing using multiple-locus, variable-number tandem repeat analysis. J Clin Microbiol 39, 31863192.

Gürcan, Ş., Karabay, O., Karadenizli, A., Karagöl, Ç., Kantardjiev, T. \& Ivanov, I. (2008). Characteristics of the Turkish isolates of Francisella tularensis. Jpn J Infect Dis 61, 223-225.

Gurycova, D. (1998). First isolation of Francisella tularensis subsp. tularensis in Europe. Eur J Epidemiol 14, 797-802.

Ikäheimo, I., Syrjälä, H., Karhukorpi, J., Schildt, R. \& Kiskeka, M. (2000). In vitro antibiotic susceptibility of Francisella tularensis isolated from humans and animals. J Antimicrob Chemother 46, 287-290.

Johansson, A., Farlow, J., Larsson, P., Dukerich, M., Chambers, E., Byström, M., Fox, J., Chu, M., Forsman, M. \& other authors (2004). Worldwide genetic relationships among Francisella tularensis isolates determined by multiple-locus variable-number tandem repeat analysis. J Bacteriol 186, 5808-5818.

Kantardjiev, T., Ivanov, I., Velinov, T., Padeshki, P., Popov, B., Nenova, R. \& Minchef, M. (2006). Tularemia outbreak, Bulgaria, 1997-2005. Emerg Infect Dis 12, 678-680.

Olsufjev, N. G. \& Meshcheryakova, I. S. (1982). Infraspecific taxonomy of tularaemia agent Francisella tularensis McCoy et Chapin. J Hyg Epidemiol Microbiol Immunol 26, 291-299.

Reintjes, R., Dedushaj, I., Gjini, A., Jorgensen, T. R., Cotter, B., Lieftucht, A., D'Ancona, F., Dennis, D. T., Kosoy, M. A. \& other authors (2002). Tularemia outbreak investigation in Kosovo: case control and environmental studies. Emerg Infect Dis 8, 69-73.

Sandström, G., Sjösted, A., Forsman, M., Pavlovich, N. \& Mishankin, B. (1992). Characterization and classification of strains of Francisella tularensis isolated in central Asian focus of the Soviet Union and Japan. J Clin Microbiol 30, 172-175.

Sjöstedt, A. B. (2005). Genus I. Francisella Dorofe'ev 1947, $176^{\mathrm{AL}}$. In Bergey's Manual of Systematic Bacteriology, 2nd edn, vol. 2, part B, pp. 200-210. Edited by D. J. Brenner, N. R. Krieg, J. T. Staley \& G. M. Garrity. New York: Springer.

Sjöstedt, A., Eriksson, U., Berglund, L. \& Tarnvik, A. (1997). Detection of Francisella tularensis in ulcers of patients with tularaemia by PCR. J Clin Microbiol 35, 1045-1048. 